\title{
TRANSLATING RESEARCH INTO PRACTICE
}

\section{Highlights in asthma 2005}

\author{
J L Heraghty, A J Henderson
}

Arch Dis Child 2006;91:422-425. doi: 10.1136/adc.2006.094094

It is usual at the end of a year for top tens to feature large in our collective consciousness. These inevitably include the occasional controversial selection and without fail will overlook a number of gems, whether in the field of literature, art, or science. The approaches to such compilations include personal selections, convening expert committees through to letting the market decide. However, it is well recognised that experts can be wrong and markets distorted. A novel approach to identifying the key publications in the field of medicine, Faculty of 1000 Medicine (http://www.f1000medicine.com), uses faculty evaluations to assign ratings to published papers within topics and categories, bringing a flavour of the dynamism of post hoc peer review to biological sciences that exists in other fields of scholarship. Archives of Disease in Childhood has also developed a market led system of peer evaluation through its web based top ten most read articles feature.

See end of article for authors' affiliations Correspondence to: Dr A J Henderson, Senior Lecturer, Department of Paediatric Respiratory Medicine, Bristol Royal Hospital for Children, Upper Maudlin Street, Bristol BS2 8BJ, UK; a.j. henderson@bris.ac.uk

Accepted 10 January 2006 ....................
O n the basis that crowds are generally smarter than individuals, ${ }^{1}$ the readership market is probably a fair discriminator of what's hot. However, in the spirit of bringing to readers' attention a selection of papers that we considered to be of interest and clinical importance during 2005, we offer this personal selection of highlights in asthma.

\section{INFLAMMOMETRY TO GUIDE ASTHMA TREATMENT}

\section{Key papers}

- Pijnenburg MW, Bakker EM, Hop WC, et al. Titrating steroids on exhaled nitric oxide in children with asthma: a randomized controlled trial. Am J Respir Crit Care Med 2005; 172:831-6.

- Smith AD, Cowan JO, Brassett KP, et al. Use of exhaled nitric oxide measurements to guide treatment in chronic asthma. $N$ Engl $J$ Med 2005;352:2163-73.

- Zacharasiewicz A, Wilson N, Lex C, et al. Clinical use of noninvasive measurements of airway inflammation in steroid reduction in children. Am J Respir Crit Care Med 2005;171:1077-82.

Efforts to develop relatively non-invasive measurements of airway inflammation in children have proceeded for a number of years. A range of methods have evolved, including induced sputum, exhaled nitric oxide, and exhaled breath condensate analysis. Much of the focus of these developments has been to better categorise airway inflammatory diseases, including asthma, in children, but a number of recent reports have suggested they may have a role in monitoring asthma control by inflammometry.

Pijnenburg and others measured the fraction of nitric oxide in exhaled air (eNO) of asthmatic children to assess whether eNO along with symptom history could be used to titrate the dose of inhaled corticosteroids in this group of children $(\mathrm{n}=39)$, compared with a control population in which the steroid dose was determined by symptoms alone $(n=46)$, over a one year period. Although the primary outcome, change in steroid dose from baseline, did not differ between groups, there was improvement in airway hyperresponsiveness in the eNO group and airway inflammation increased in the symptom treated group. ${ }^{2}$ The lack of reduction in steroid dose was disappointing as this approach had been successful in other studies including mainly adult subjects. ${ }^{3}$ Smith and colleagues reported a randomised trial in 97 adolescents and adults of conventional management or inclusion of eNO in determining inhaled steroid dose. In the eNO group the mean daily dose of fluticasone was $370 \mu \mathrm{g}$ compared with $641 \mu \mathrm{g}$ in the standard management group $(p=0.003)$, despite the absence of differences in markers of disease control, such as pulmonary function, use of systemic steroids, or levels of airway inflammation assessed by sputum eosinophils. It is still unclear why this approach to steroid reduction resulted in apparently different outcomes in adults and children.

In a separate study, a group of 48 children with stable asthma who were clinically eligible for inhaled steroid dose reduction were reviewed every eight weeks, and their inhaled steroid dose was halved when possible. ${ }^{4}$ At each assessment eNO, sputum induction combined with bronchial hyperreactivity testing, and exhaled breath condensate collections were performed. Thirty of 40 (75\%) children tolerated at least one dose reduction and 12 of these children were successfully weaned off inhaled steroids completely. In all cases, the absence of eosinophils detected in induced sputum was associated with successful reduction of steroid dose. Increased eNO and sputum eosinophilia were significant predictors of a relapse after reduction of steroid dose.

Taken together these results suggest that monitoring eNO and sputum eosinophils may have a clinical role in predicting response to reducing inhaled steroid treatment in children with asthma and possibly in limiting or reducing 
steroid doses prescribed. They are also likely to have an important role in identifying patients for inclusion in trials of novel asthma therapies as these evolve, such as anti-TNF $\alpha$ treatment. ${ }^{5}$ The advent of relatively inexpensive hand held analysers to measure eNO in children, at an estimated cost of $£ 5$ per test, ${ }^{6}$ and the extension of measurement methods to preschool children ${ }^{7}$ and infants ${ }^{8}$ are likely to increase the utility of this measurement in research and clinical studies of asthma in the paediatric age group.

\section{DOES MILD ASTHMA NEED REGULAR TREATMENT WITH STEROIDS?}

\section{Key paper}

- Boushey HA, Sorkness CA, King TS, et al. Daily versus asneeded corticosteroids for mild persistent asthma. $N$ Engl $J$ Med 2005;352:1519-28.

In the stepwise approach to asthma management, daily inhaled steroids provide the mainstay of the BTS guidelines. Regular preventative treatment is recommended to reduce symptoms and avoid exacerbations ${ }^{9}$ in children with more than mild, intermittent asthma. However, a frequently reported barrier to implementation of this guideline is the question of patient and family adherence to prescribed asthma medications. In a study of adults with mild asthma, Boushey and others have reported the results of a trial of intermittent asthma therapy compared with daily inhaled steroids or daily leukotriene receptor antagonist therapy. ${ }^{10}$

A population of 225 adults with mild persistent asthma were randomised to one of three intervention groups: intermittent inhaled budesonide, regular daily inhaled budesonide, and daily zafirlukast. The primary outcome, morning peak expiratory flow, showed no difference between the three groups, with similar increases of approximately $32 \mathrm{l} / \mathrm{min}(\mathrm{p}=0.90)$ over the 12 month trial period. Secondary outcomes included the number of asthma exacerbations, which also did not differ between the three groups $(p=0.24)$, even though the intermittent therapy group took inhaled steroids for an average of only 0.5 weeks of the year. An exacerbation was defined on the basis of initiation of prednisolone based on an asthma action plan and only occurred in $11 \%$ of the patients, confirming that this was a population with relatively mild disease. The authors concluded that it might be possible to use short courses of inhaled or oral corticosteroids when symptoms worsen rather than regular daily therapy in this group of patients.

However, despite their confidence in the apparent success of the trial, most of the other study outcome variables showed a greater benefit in the daily budesonide group. These included greater improvements in pre-bronchodilator $\mathrm{FEV}_{1}(\mathrm{p}=0.005)$, bronchial reactivity $(\mathrm{p}<0.001)$, percentage of eosinophils in sputum $(p=0.007)$, exhaled nitric oxide levels $(p=0.006)$, scores for asthma control $(\mathrm{p}<0.001)$, and the number of symptom-free days $(p=0.03)$. This translates to 26 extra symptom-free days in the budesonide therapy group (95\% CI 1.8 to 48.5 ).

The advantage of less steroid use is obvious, but this study does not show convincing evidence for the use of intermittent inhaled steroids and cannot be extrapolated directly to children, where assessing symptoms may be more difficult and the pattern of mild persistent asthma less prevalent. However, the concept of targeted, intermittent therapy compared with regular daily treatment is perhaps one that should be explored further, particularly for children with mild asthma or in those whose symptoms are confined to discrete seasonal exacerbations.

\section{EXERCISE INDUCED ASTHMA}

\section{Key paper}

- Seear M, Wensley D, West N. How accurate is the diagnosis of exercise induced asthma among Vancouver schoolchildren? Arch Dis Child 2005;90:898-902.

Exercise induced bronchoconstriction has long been regarded as a hallmark of childhood asthma. It is a common symptom, affecting up to $10-15 \%$ of the population depending on the definition and populations studied, and has been used as a marker of asthma in epidemiological surveys of changing prevalence. Seear and colleagues have recently re-examined the accuracy of diagnosing exercise induced asthma in a population of Vancouver schoolchildren. ${ }^{11}$ They studied 52 children who were referred for investigation of poorly controlled exercise induced asthma (EIA). The group underwent history, examination, and pulmonary function testing before, then 5 and 15 minutes after a standardised treadmill test. Only $15.4 \%$ had a fall in $\mathrm{FEV}_{1}$ of greater than $10 \%$, fulfilling the diagnostic criteria of EIA. The remainder either had an alternative diagnosis, vocal cord dysfunction (26.9\%), were unfit $(23.1 \%)$, had a habitual cough $(13.5 \%)$, or no abnormality could be demonstrated $(21.1 \%)$. They concluded that the clinical diagnosis of EIA is inaccurate in this population of children mainly due to the unreliability of their initial exercise related complaints.

Elite athletes often report EIA; this population included 8 of the 52 children referred. Nearly $75 \%$ of these subjects were subsequently diagnosed as having vocal cord dysfunction. It has previously been acknowledged that there may be potential for abuse of $\beta_{2}$ agonists in asthmatic athletes as they could provide an ergometric advantage. ${ }^{12}{ }^{13}$ The problems for those with undiagnosed conditions, especially in those that are physically fit, may be that we cannot recreate in the laboratory the conditions that are reported to cause bronchoconstriction during activities, such as swimming or outdoor aerobic exercise in cold conditions. However, it is important to consider other diagnoses in this context, particularly when there is reported failure to respond to increasing asthma treatment.

This study continues to emphasise the controversy around EIA but only confirms reports from previous studies. ${ }^{14}$ It again draws attention to the problems of accurate diagnosis in a group of medically educated patients explaining their symptoms and the continuing need for accurate history and examination.

\section{MAGNESIUM SULPHATE FOR THE TREATMENT OF ACUTE ASTHMA EXACERBATIONS}

\section{Key paper}

- Cheuk DK, Chau TC, Lee SL. A meta-analysis on intravenous magnesium sulphate for treating acute asthma. Arch Dis Child 2005;90:74-7.

In the acute management of asthma exacerbations there has been much debate about the effectiveness of intravenous magnesium sulphate in children. Previous reviews have focused mainly on adult patients. ${ }^{15}$ A systematic review of the literature by Cheuk and others identified five randomised placebo controlled clinical trials involving children which included 182 patients. ${ }^{16}$ They compared intravenous magnesium sulphate with placebo in treating paediatric patients with moderate to severe asthmatic attacks in the emergency department, alongside inhaled $\beta_{2}$ agonists and systemic steroids. The studies were of high quality with results judged to be valid by two independent reviewers. 
Four studies reported that magnesium sulphate was effective, ${ }^{17-20}$ while one study found no benefit ${ }^{21}$ in the primary outcome of need for hospitalisation (odds ratio $0.290,95 \%$ CI 0.143 to 0.589 ). The number needed to treat was 4 (95\% CI 3 to 8$)$. Secondary outcomes suggested approximately $85 \%$ reduction in persistent bronchoconstriction with PEFR $<60 \%$ of predicted values, and significant symptomatic improvement.

These observations have naturally led to consideration of inhaled magnesium sulphate as an adjunct to $\beta_{2}$ adrenergic agonists for the treatment of acute asthma. ${ }^{22}$ Although the majority of these studies recruited adult patients (three adult, two paediatric, one both), there appeared to be no subgroup differences based on age. Results of the meta-analysis showed no benefit in the rate of hospitalisation but statistically significant improvements in pulmonary function. Differences in study protocols make it difficult to directly compare studies but the effects appeared to be maximal soon after treatment. There was no evidence for the use of inhaled magnesium as an alternative to inhaled $\beta_{2}$ agonists.

In conclusion, inhaled and intravenous magnesium sulphate probably provide additional benefit in moderate to severe acute asthma in children treated with bronchodilators, although intravenous therapy appears to have more benefit than inhaled therapy in prevention of hospitalisation. However, in keeping with many asthma intervention studies in emergency department settings, the impact on intermediate outcomes, such as length of hospital stay or intensive care admissions, is not apparent. This is likely to reflect methodological issues, such a single dose or short-term therapeutic study designs that lend themselves to this clinical setting and to recruitment of populations with moderate asthma exacerbations. A different but equally important clinical question is whether novel therapeutic agents have lasting benefits when used singly or repeatedly in subjects admitted to hospital with more severe asthma; such studies are likely to require multicentre collaborations to recruit sufficient subjects. The Medicines for Children Research Network (MCRN) in the United Kingdom is to be welcomed as one route through which this sort of study might be channelled in the future.

\section{CAN SEX HORMONES EXPLAIN GENDER DIFFERENCES IN ASTHMA EPIDEMIOLOGY?}

\section{Key papers}

- Mandhane PJ, Greene JM, Cowan JO, et al. Sex differences in factors associated with childhood- and adolescent-onset wheeze. Am J Respir Crit Care Med 2005; 172:45-54.

- Hancox RJ, Milne BJ, Poulton R, et al. Sex differences in the relation between body mass index and asthma and atopy in a birth cohort. Am J Respir Crit Care Med 2005; 171:440-5.

Epidemiological studies have reported a number of important sex differences in asthma outcomes. It is tempting to speculate that this signifies a role of sex steroids in the development of asthma or atopy. This topic has received considerable recent attention with separate studies reporting associations between sex, increased BMI, early menarche, irregular periods, and the rates and severity of asthma.

A large New Zealand birth cohort of just over one thousand participants has been followed for 26 years and assessed for the development of wheeze. Males were significantly more likely to develop wheeze in early childhood (less than 10 years), whereas females had a higher incidence during the adolescent years, consistent with reports from previous studies. ${ }^{23}$ The authors assessed the association with parental atopy and found the strongest association was between paternal atopy and asthma in their daughters. The study group suggested that this association might be because asthma is an X-linked recessive disorder and that gene products are influenced by changes in sex hormones present during adolescence.

The same researchers also studied the association between asthma, atopy, and body mass index and reported that a raised BMI was a risk factor for asthma in women but not in men, ${ }^{24}$ to the extent that overweight in females after the age of 9 years contributes as much as $28 \%$ (95\% CI 7 to 45 ) of the risk of developing asthma. This study used self-reported diagnosis of asthma which could have led to misclassification of true asthma and dyspnoea associated with poor aerobic fitness; this being supported in part by the lack of association between BMI and airway hyperresponsiveness in the study. However, such confounders would not explain the observed statistically significant association of increased BMI with raised serum IgE and atopy diagnosed on skin prick testing in females.

Other groups have reported similar associations. In a French study, asthma severity, which was unrelated to sex, increased with BMI in women $(p=0.0001)$ but not in men $(p=0.3)$. In women, the association remained after adjustment for age, $\mathrm{FEV}_{1}$, smoking habits, and BMI adjusted dyspnoea and taking into account familial dependence $(\mathrm{p}=0.0001) .{ }^{25}$ This association between BMI and severity was stronger in women with early menarche, further supporting the possibility of sex specific hormonal factors being involved in the regulation of allergic inflammation.

Another piece of this jigsaw comes from a postal questionnaire study sent to over eight thousand Scandinavian women. The responses supported an association between irregular menstruation and asthma (OR 1.54), asthma symptoms (OR 1.47), hay fever (OR 1.29), and asthma preceded by hay fever (OR 1.95) among women aged 26-42 years, but not in older women. The association could possibly be explained by common underlying metabolic or developmental factors. The authors hypothesise that insulin resistance may play a role in asthma and allergy. ${ }^{26}$ These and earlier epidemiological observations, complemented by experimental studies of immune mediating effects of sex hormones in vivo and in vitro, suggest that sex hormones play at least a part in determining some of the gender differences in the natural history of asthma. On this basis, sex steroid metabolism has been suggested as a potential therapeutic target in asthma. ${ }^{27}$ Whether it also has a role in primary prevention remains to be seen.

\section{REFLUX REVISITED: DOES TREATMENT OF GASTRO- OESOPHAGEAL REFLUX HELP ASTHMA SYMPTOMS?}

\section{Key paper}

- Stordal K, Johannesdottir GB, Bentsen BS, et al. Acid suppression does not change respiratory symptoms in children with asthma and gastro-oesophageal reflux disease. Arch Dis Child 2005;90:956-60.

There remains considerable doubt about whether a causal relationship exists between gastro-oesophageal reflux and asthma symptoms. It seems logical that microaspiration into the airways could provoke bronchoconstriction and airway inflammation and there is some experimental and observational evidence to support this, ${ }^{28}$ but little evidence from clinical trials that treating gastro-oesophageal reflux reduces asthma symptoms. A previous study in children has reported modest but statistically significant improvement in nocturnal asthma symptoms with ranitidine treatment, ${ }^{29}$ leading the 
authors to suggest that a trial of more potent acid suppression might be warranted. Such a study using omeprazole has now been reported..$^{30}$

Thirty eight children with asthma and gastro-oesophageal reflux (reflux index of at least 5.0) were randomised to 12 weeks of treatment with omeprazole or placebo. The change in total asthma symptom score did not differ significantly between the omeprazole and the placebo group. There was no change in lung function and no difference in the use of short acting bronchodilators between the groups. A repeat $\mathrm{pH}$ study at the end of the trial confirmed acid suppression was adequate with a normal reflux index in the omeprazole treated patients. In conclusion, omeprazole treatment did not improve asthma symptoms or lung function in children with asthma and gastro-oesophageal reflux disease.

Reflux studies are often performed in children with asthma and treatment started on the basis of abnormal reflux indices. This study suggests treatment may be unnecessary if the aim of treatment is to improve asthma control rather than to manage reflux symptoms.

\section{CONCLUSION}

As we stated at the outset, this selection was intended to draw attention to a number of clinically important and topical areas of asthma research. Papers were selected on this basis rather than appearing in the highest impact or most widely read medical journals. It was our intention to both highlight clinical trials that may be of relevance now or in the future to children with asthma and, at the same time, to give a flavour of new developments in understanding asthma pathophysiology, for example by measuring airway inflammation, that may have implications for future management strategies. Like all lists, we are sure that this one will have its supporters and detractors. Perhaps the message should be to keep track of initiatives like Faculty of 1000 Medicine (http:// www.f1000medicine.com), launched this year, as another method of keeping the practising clinician abreast of what's new and important in clinical and laboratory research.

\section{Authors' affiliations}

J L Heraghty, A J Henderson, Department of Paediatric Respiratory Medicine, Bristol Royal Hospital for Children, Bristol, UK

Competing interests: none declared

\section{REFERENCES}

1 Surowiecki J. The wisdom of crowds. London: Little Brown, 2004.

2 Pijnenburg MW, Bakker EM, Hop WC, et al. Titrating steroids on exhaled nitric oxide in children with asthma: a randomized controlled trial. Am J Respir Crit Care Med 2005; 172:831-6.

3 Smith AD, Cowan JO, Brassett KP, et al. Use of exhaled nitric oxide measurements to guide treatment in chronic asthma. N Engl J Med 2005;352:2163-73

4 Zacharasiewicz A, Wilson N, Lex C, Erin EM, et al. Clinical use of noninvasive measurements of airway inflammation in steroid reduction in children. Am J Respir Crit Care Med 2005;171:1077-82.
5 Howarth PH, Babu KS, Arshad HS, et al. Tumour necrosis factor (TNFalpha) as a novel therapeutic target in symptomatic corticosteroid dependent asthma. Thorax 2005:60:1012-18.

6 National Horizon Scanning Centre. NIOX MINO airway inflammation monitor for the diagnosis and monitoring of asthma-horizon scanning review. Birmingham: National Horizon Scanning Centre (NHSC), 2005:7.

7 Napier E, Turner SW. Methodological issues related to exhaled nitric oxide measurement in children aged four to six years. Pediatr Pulmonol 2005;40:97-104.

8 Franklin PJ, Turner SW, Mutch RC, et al. Comparison of single-breath and tidal breathing exhaled nitric oxide levels in infants. Eur Respir J 2004;23:369-72

9 British Thoracic Society, Scottish Intercollegiate Guidelines Network (SIGN). British guideline on the management of asthma. Thorax 2003;58(suppl 1): i $1-94$.

10 Boushey HA, Sorkness CA, King TS, et al. Daily versus as-needed corticosteroids for mild persistent asthma. N Engl J Med 2005;352:1519-28.

11 Seear M, Wensley D, West N. How accurate is the diagnosis of exercise induced asthma among Vancouver schoolchildren? Arch Dis Child 2005;90:898-902.

12 Helms PJ. Exercise induced asthma: real or imagined? Arch Dis Child 2005;90:886-7.

13 Martineau L, Horan MA, Rothwell NJ, et al. Salbutamol, a beta 2adrenoceptor agonist, increases skeletal muscle strength in young men. Clin Sci 1992;83:615-21.

14 Hallstrand TS, Curtis JR, Koepsell TD, et al. Effectiveness of screening examinations to detect unrecognised exercise-induced bronchoconstriction. J Pediatr 2002;141:343-8.

15 Rowe BH, Bretzlaff JA, Bourdon C, et al. Intravenous magnesium sulfate treatment for acute asthma in the emergency department: a systematic review of the literature. Ann Emerg Med 2000;36:181-90.

16 Cheuk DK, Chau TC, Lee SL. A meta-analysis on intravenous magnesium sulphate for treating acute asthma. Arch Dis Child 2005;90:74-7.

17 Ciarallo L, Sauer AH, Shannon MW. Intravenous magnesium therapy for moderate to severe pediatric asthma: results of a randomized, placebocontrolled trial. J Pediatr 1996;129:809-14.

18 Ciarallo L, Brousseau D, Reinert S. Higher-dose intravenous magnesium therapy for children with moderate to severe acute asthma. Arch Pediatr Adolesc Med 2000; 154:979-83.

19 Devi PR, Kumar L, Singhi SC, et al. Intravenous magnesium sulfate in acute severe asthma not responding to conventional therapy. Indian Pediatr 1997;34:389-97.

20 Gurkan F, Haspolat K, Bosnak M, et al. Intravenous magnesium sulfate in the management of moderate to severe acute asthmatic children non-responding to conventional therapy. Eur J Emerg Med 1999;6:201-5.

21 Scarfone RJ, Loiselle JM, Joffe MD, et al. A randomized trial of magnesium in the emergency department treatment of children with asthma. Ann Emerg Med 2000;36:572-8.

22 Blitz M, Blitz S, Beasley R, et al. Inhaled magnesium sulfate in the treatment of acute asthma. Cochrane Database of Systematic Reviews 2005;3.

23 Mandhane PJ, Greene JM, Cowan JO, et al. Sex differences in factors associated with childhood- and adolescent-onset wheeze. Am J Respir Crit Care Med 2005; 172:45-54.

24 Hancox RJ, Milne BJ, Poulton R, et al. Sex differences in the relation between body mass index and asthma and atopy in a birth cohort. Am J Respir Crit Care Med 2005;171:440-5.

25 Varraso R, Siroux V, Maccario J, et al. Asthma severity is associated with body mass index and early menarche in women. Am J Respir Crit Care Med 2005; 171:334-9.

26 Svanes C, Real FG, Gislason T, et al. Association of asthma and hay fever with irregular menstruation. Thorax 2005;60:445-50.

27 Osman M. Therapeutic implications of sex differences in asthma and atopy. Arch Dis Child 2003;88:587-90.

28 Stein MR. Possible mechanisms of influence of esophageal acid on airway hyperresponsiveness. Am J Med 2003;1 15(suppl 3A):55S-59S.

29 Gustafsson PM, Kjellman NI, Tibbling L. A trial of rantidine in asthmatic children and adolescents with or without pathological gastro-oesophageal reflux. Eur Respir J 1992;5:201-6.

30 Stordal K, Johannesdottir GB, Bentsen BS, et al. Acid suppression does not change respiratory symptoms in children with asthma and gastrooesophageal reflux disease. Arch Dis Child 2005;90:956-60. 